San Jose State University

SJSU ScholarWorks

Master's Theses

Master's Theses and Graduate Research

1993

\title{
The Relationship of health locus of control and treatment adjustment in chronic hemodialysis
}

\author{
Melinda Zimmer-Rankin \\ San Jose State University
}

Follow this and additional works at: https://scholarworks.sjsu.edu/etd_theses

\section{Recommended Citation}

Zimmer-Rankin, Melinda, "The Relationship of health locus of control and treatment adjustment in chronic hemodialysis" (1993). Master's Theses. 663.

DOI: https://doi.org/10.31979/etd.y72a-2was

https://scholarworks.sjsu.edu/etd_theses/663

This Thesis is brought to you for free and open access by the Master's Theses and Graduate Research at SJSU ScholarWorks. It has been accepted for inclusion in Master's Theses by an authorized administrator of SJSU ScholarWorks. For more information, please contact scholarworks@sjsu.edu. 


\section{INFORMATION TO USERS}

This manuscript has been reproduced from the microfilm master. UMI films the text directly from the original or copy submitted. Thus, some thesis and dissertation copies are in typewriter face, while others may be from any type of computer printer.

The quality of this reproduction is dependent upon the quality of the copy submitted. Broken or indistinct print, colored or poor quality illustrations and photographs, print bleedthrough, substandard margins, and improper alignment can adversely affect reproduction.

In the unlikely event that the author did not send UMI a complete manuscript and there are missing pages, these will be noted. Also, if unauthorized copyright material had to be removed, a note will indicate the deletion.

Oversize materials (e.g., maps, drawings, charts) are reproduced by sectioning the original, beginning at the upper left-hand corner and continuing from left to right in equal sections with small overlaps. Each original is also photographed in one exposure and is included in reduced form at the back of the book.

Photographs included in the original manuscript have been reproduced xerographically in this copy. Higher quality $6^{\prime \prime} \times 9^{\prime \prime}$ black and white photographic prints are available for any photographs or illustrations appearing in this copy for an additional charge. Contact UMI directly to order.

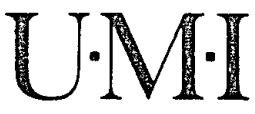



Order Number 1354178

The relationship of health locus of control and treatment adjustment in chronic hemodialysis

Zimmer-Rankin, Melinda, M.S.

San Jose State University, 1993 
THE RELATIONSHIP OF HEALTH LOCUS OF CONTROL AND TREATMENT ADJUSTMENT IN CHRONIC HEMODIALYSIS

\author{
A Thesis \\ Presented to \\ The Faculty of the Department of Nursing \\ San Jose state University
}

in Partial Fulfillment

of the Requirements for the Degree

Master of Science

by

Melinda zimmer-Rankin

August, 1993 
APPROVED FOR THE DEPARTMENT OF NURSING Emilie Muse

Emilie Musci, D.N.SC., R.N.

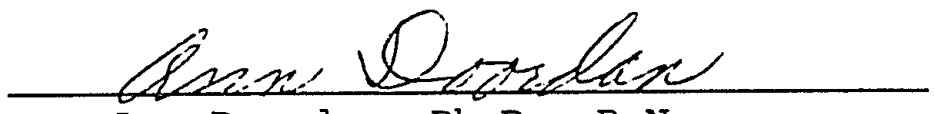
Ann Doordan, Ph.D., R.N.

Saly butrou-Hedon-

Sally. Burrow-Hudson, M.S.N., R.N.

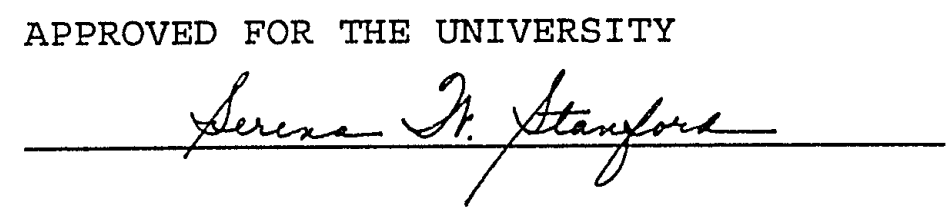


ASTRACT

THE RELATIONSHIP OF HEALTH LOCUS OF CONTROL AND TREATMENT ADJUSTMENT IN CHRONIC HEMODIALYSIS

by Melinda zimmer-Rankin

This study explored the relationship between locus of control (LOC) and adjustment to the prescribed treatment regimen in chronic hemodialysis patients. The two areas of treatment adjustment examined were dietary compliance and fluid restriction as measured by serum potassium, phosphorus, urea nitrogen levels, and interdialytic weight gains. Using the Multidimensional Health Locus of Control scale Questionnaire (MHLC) and chart reviews, data were collected and analyzed from 31 hemodialysis patients.

The data showed there was not a strong relationship between internal IOC and any physiological indicator of treatment adjustment. External LOC and powerful other LOC were significantly correlated with a decrease in BUN $(\underline{r}=-.42, \underline{p}=.02$ and $\underline{r}=-.57, \underline{p}=.0008)$. The results suggest that beliefs about the control one has over their health is not a primary influence upon adjustment or adherence to the prescribed treatment regimen. Future investigations into treatment adjustment to the prescribed regimen of chronic hemodialysis should consider additional factors which may influence compliance in this population. 


\section{ACKNOWLEDGEIMENTS}

To my husband, whose love and support have made it possible for me to reach out for acheivements beyond the expected. To the faculty at San Jose state University, whose time in editing this thesis was appreciated. 
TABLE OF CONTENTS

Page

LIST OF TABLE . . . . . . . . . . . . . . . . . . . . . . viii Chapter

1. INTRODUCTION . . . . . . . . . . . . 1 Problem . . . . . . . . . . . . . 2 Purpose • . . • . • . . . . . . . 6

Research Question and Sub Questions . . . 6

Definitions of Terms . . . . . . . . . 7

Summary • . . . . . . . . . . . . . 9

2. CONCEPTUAL FRAMEWORK AND REVIEW OF RELATED

LITERATURE . . . . . . . . . . . . 11

Background Information . . . . . . . . 11

Conceptual Framework . . . . . . . . . 14

Literature Review . . . . . . . . . 16

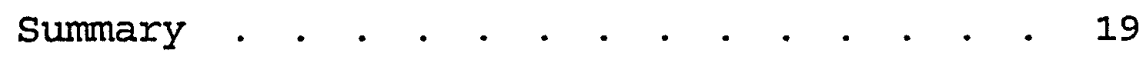

3. METHODOLOGY • . . . . . . . . . . 20

Research Design . . . . . . . . . . 20

Human Subject Approval . . . . . . . . 20

Setting • • • • • • • • • • • • • 21

Sample size and sample selection . . . . 21

Multidimensional Health Locus of Control

Questionnare . . . . . . . . . . . 23

Data Collection . . . . . . . . . . 25 
Data Analysis . . . . . . . . . . . . . 27

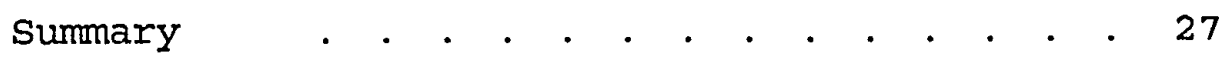

4. ANALYSES AND INTERPRETATION OF DATA . . . 28 Data Collection . . . . . . . . . . 28

Demographic Characteristics . . . . . 29

Locus of Control. . . . . . . . . . 33

Summary • • • • • • • • • • . • • 36

5. DISCUSSION, IMPLICATIONS AND

RECOMMENDATIONS . . . . . . . . . . . 38

Summary . . . . . . . . . . . . . . 38

Irimitations . . . . . . . . . . . . 39

Recommendation for Further study . . . . 41

Implications for Nursing Practice. . . . 43

Conclusion . . . . . . . . . . . . . . 45

REFERENCES . . . . . . . . . . . . . . . . . .

APPENDIXES

A. San Jose State University's Human

Subjects-Institutional Review Board Approval . . . . . . . . . . . 53

B. Agency's Institutional Review Board

Approval . . . . . . . . . . 55

C. Addendum . . . . . . . . . . . . 57

D. Letter of Support from Physicians . . 59

vi 
E. Cover Letter and Consent Form. . . . 61

F. Multidimensional Health Locus of Control

Scale Questionnaire. . . . . . 65

G. Permission to Use the MHLC

Questionnaire . . . . . . . . 69

H. Chart Review Collection Form . . . . 71

vii 


\section{LIST OF TABLES}

Table Page

1. Demographic Characteristics of the Sample 31

2. Physiological Indicators of Treatment Adjustment . . . . . . . . . . . . 32

3. Multidimensional Health Locus of Control . 34

4. Correlations Between Physiological Indicators of Treatment Adjustment and Locus of Control . . . . . . . . 35 


\section{Chapter 1}

\section{INTRODUCTION}

The annual data report from the Transpacific Renal Network of Northern California indicated that as of December 31, 1991, there were 130,097 individuals diagnosed with end stage renal disease (ESRD) on some form of dialysis in order to sustain 1ife. According to Speroles (1977) the National Dialysis Registry reported only 29,182 patients on chronic hemodialysis in the United States in January of 1977. In less than 15 years the number of individuals on chronic hemodialysis had increased to 116,847 (TransPacific Renal Network, 1991).

With the advent of hemodialysis as a method to sustain life, an ever increasing population who would have otherwise died now live in "abject dependence upon a machine and a prescribed treatment regimen" (Levy, 1974). The chronic hemodialysis population is comprised of individuals from a variety of cultural, educational, and financial backgrounds. The diversity, the growing size of this population, and the mortality associated with this disease reveal the need for planning and research to meet projected health care needs. Problem

The problem to be examined in this study is the potential influence an individual's locus of control (LOC) 
has on adjustment to the prescribed treatment regimen of chronic hemodialysis. The ability to adjust to the prescribed treatment protocol differs among individuals and may depend upon certain aspects of the regimen such as fluid and dietary restrictions (Wolcott, Maida, Diamond, \& Nissenson, 1986). In addition, various psychological stressors may impact an individual's ability to cope with the demands of chronic hemodialysis.

Failure to comply with various aspects of the treatment regimen, such as dietary compliance and fluid restriction, may result in serious, life threatening crises and a potentially decreased survival time. The two primary complications related to noncompliance to the prescribed fluid and dietary protocol and requiring immediate medical and nursing interventions are: (a) hyperkalemia and (b) pulmonary edema (Lancaster, 1987). Hyperkalemia is the most serious electrolyte problem associated with renal failure. It is a condition that results from too much potassium in the blood due to the following: (a) failure of the excretory ability of the kidneys, (b) breakdown of cellular protein which releases potassium, (c) acidosis, and (d) excesssive potassium intake (Lewis \& Collier, 1992). Hyperkalemia may precipitate cardiac dysrhythmias, cardiac arrest, and death. Pulnonary edema results from the accumulation of extravascular fluid in the alveoli of the 
lungs causing severe shortness of breath and dyspnea which may lead to hypoxemia, respiratory failure, and death (Urdang \& Swallow, 1983). Pulmonary edema may be linked to excessive fluid intake in the chronic hemodialysis population.

Inability to adjust to the prescribed treatment regimen may exacerbate other physiological complications which include hypertension, neuropathy, and renal osteodystrophy. Hypertension is an elevated blood pressure due to the kidney's inability to excrete sodium and water (Lancaster, 1987). Hypertension can partially be controlled by sodium and fluid restriction. Neuropathy is initially manifested by a slowing of nerve conduction to the extremities. It may lead to muscle weakness and paresthesia which sometimes require the use of braces, walkers, or crutches for ambulation (Hudak, Gallor, \& Lohr, 1986). The exact cause of neuropathy is unknown, however, it may be exacerbated in the presence of severe or chronic uremia (Lewis \& Collier, 1992). Uremia is the accumulation of nitrogenous waste products which causes physiologic changes and alters the function of various organ systems. The end products of nitrogen breakdown are directly proportional to one's protein intake (Lancaster, 1987). Renal osteodystrophy is a bone disease that occurs from an imbalance of calcium and phosphorus associated with end stage renal disease (Hudak et 
al., 1986). Renal osteodystrophy causes demineralization of the bones which may lead to spontaneous fractures. In addition, the imbalance between phosphorus and calcium may lead to the formation of calcium phosphate crystals that deposit in various parts of the body, especially the brain, eyes, lung, and myocardium (Lancaster, 1987).

Adjustment to the prescribed treatment regimen has been a prime health care issue in the chronic hemodialysis population over the past few decades. Past research studies have focused on: (a) situational factors (Cummings, Becker, Kirscht, \& Levin, 1982; Procci, 1978), (b) characteristics of the treatment regimen (Blackburn, 1977; Hartman \& Becker, 1978; Kaplan De-Nour, 1981), (c) demographic elements (Brock, 1990; Cumming et al., 1982; Procci, 1978, 1981), and (d) patient-physician interaction (Kirilloff, 1981).

Theoretical models that explored hemodialysis compliance have included: (a) health beliefs and health promotion (Bandura, 1976, 1977; Cummings et al., 1982; Hartman \& Becker, 1978), (b) sociocultural, learning theory, cognitive theory (Blackburn, 1977; Kaplan De-Nour \& Czaczkes, 1976; Kirilloff, 1981; Levy, 1980; Procci, 1.981); and (c) personality traits (Poll \& Kaplan De-Nour 1980; Rosenstock, Strecher \& Becker, 1988; Rotter, 1954, 1966; zetin, Plummer, Vaziri, \& Cramer, 1981). 
Psychiatrists have played an active role in identifying and treating various psychological factors and personality traits associated with the inability to adhere and adjust to the prescribed regimen in chronic hemodialysis patients. Sand, Livingston, and Wright (1966) were among the first to note psychological factors as influential elements in determining adjustment to various aspects of the hemodialysis regimen. Later reports concentrated on the perceptions, anxieties, and stresses associated with chronic dialysis (Procci, 1978). More recent studies have gathered information about specific personality characteristics such as locus of control and cognitive variables which may promote or hinder treatment adjustment (Brock, 1990; Brown \& Fitzpatrick, 1988; Levin \& Schulz, 1980; Poll \& Kaplan De-Nour, 1980; Zetin et al., 1981).

The problems associated with treatment adjustment to the prescribed regimen of chronic hemodialysis are widespread. There may be significant individual differences in the level of adjustment depending upon different aspects of the regimen. The diversity of the chronic hemodialysis population, in addition to the complexity of the treatment regimen, makes it difficult to create a standard profile to identify all individuals at risk of engaging in behaviors associated with noncompliance. However, the life threatening implications of noncompliance to the prescribed 
treatment regimen calls for future planning and research to prevent complications and promote behaviors conducive to treatment adjustment.

\section{Purpose}

The purpose of this study was to explore the relationship between a psychological concept, locus of control, and the ability to comply with the prescribed treatment regimen in 31 chronic hemodialysis patients. The ability to comply to the prescribed treatment regimen was measured by the following: (a) predialysis serum potassium (K) levels, (b) serum phosphorus (P) levels, (C) blood urea nitrogen (BUN) levels, and (d) interdialytic weight gains (IWG). The individual's self-reported health locus of control (HLOC) was derived from the total points scored on an 18 item multidimensional health locus of control questionnaire.

Research Question

The question that guided this research was: What is the relationship between locus of control and adjustment to the prescribed treatment regimen in chronic hemodialysis patients?

Sub Questions

1. What is the relationship between locus of control and predialysis serum potassium levels? 
2. What is the relationship between locus of control and predialysis serum phosphorus levels?

3. What is the relationship between locus of control and predialysis blood urea nitrogen levels?

4. What is the relationship between locus of control and interdialytic weight gain?

\section{Definitions of Terms}

1. End-stage renal disease (ESRD) occurs when the kidneys are no longer functioning sufficiently to support life. The kidneys are unable to filter excess fluid and waste products, regulate fluid and electrolytes, regulate blood pressure, or stimulate the production of red blood cells (RBC).

2. Hemodialysis is a method of using an artificial kidney machine and an artificial kidney (dialyzer) to remove excess fluid and waste products from the blood. The treatment generally takes 3-4 hours and must be done routinely 3 times a week.

3. Chronic hemodialysis patient is an individual who has been medically diagnosed as having ESRD and requires hemodialysis to sustain life.

4. Prescribed treatment regimen includes hemodialysis treatments 3 times per week, a diet low in potassium and protein, and a fluid restriction of 1000-1500 CC per day. 
5. Optimum physiological treatment adjustment is defined by the criteria established by Wenorowicz, Riskind, and Jenkins (1978). These criteria were measurements of:

(a) predialysis serum potassium (K) less than $5.5 \mathrm{meq} / \mathrm{l}$,

(b) predialysis serum phosphorus (P) less than $4.5 / \mathrm{dl}$,

(c) predialysis serum urea nitrogen (BUN) less than

$100 \mathrm{mg} / \mathrm{dl}$, and (d) interdialytic weight gain (IWG) less than

2.6 kilograms. Furthermore, it includes those behaviors undertaken by an individual to maintain an optimal level of physical well-being (e.g., adhering to prescribed treatment regimen).

6. Interdialytic weight gain (IWG) is the amount of weight that is gained in between dialysis treatment.

7. Uremia is the presence of excessive amounts of urea and other nitrogenous waste products in the blood as compared to normal blood values. Historically, increased protein catabolism has been associated with the severity of clinical manifestations of uremia. Urea is the bulk catabolite of protein. Blood urea nitrogen (BUN) concentration is generally considered a non toxic solute except at very high levels (Lancaster, 1987).

8. $\underline{K t / V}$ is a symbol showing part of the urea kinetic model. It is a mathematical description of input, output, and accumulation of urea in patients with chronic renal failure or end stage renal disease. $\mathrm{Kt} / \mathrm{V}$ was developed as 
an index of dialysis adequacy. $\mathrm{Kt} / \mathrm{V}$ is the dialyzer urea clearance value multiplied by the length of dialysis then divided by the patient's volume. For example: dialyzer urea clearance is $170 \mathrm{ml} / \mathrm{min}$ or 0.170 liters $/ \mathrm{min}$; treatment time is 3 hours or 180 minutes; the patient's volume is 30 liters, then: $\mathrm{Kt} / \mathrm{V}=(.170)(180) / 30=1.02$. A dialysis prescription providing a $\mathrm{Kt} / \mathrm{V}$ greater than 1.0 reduces the risk of uremic complications in chronic hemodialysis patients (Lancaster, 1987).

9. Health Locus of Control (HLC) refers to the degree to which individuals perceive events in their lives as being a consequence of their own actions (Wallston \& Wallston, 1978). An individual with an internal locus of control believes that his/her actions have causal relationships which produce outcomes. On the other hand, a person with an external locus of control relates events and outcomes to forces such as fate, chance, or powerful others (Rotter, 1966).

\section{Summary}

The anticipated benefit of the study is improved understanding of the relationship between locus of control and the ability to adjust to the prescribed treatment regimen in the chronic hemodialysis population. This knowledge may serve as a basis for identification of individuals at risk of engaging in behaviors that may 
precipitate serious life threatening complications.

Moreover, it will aid in the development of readily needed education strategies designed to teach health behaviors that will promote treatment adjustment and, therefore, maximize health. 


\section{Chapter 2}

\section{CONCEPTUAL FRAMEWORK AND REVIEW OF LITERATURE}

This chapter begins with background information that describes the complexity associated with treatment adjustment to the prescribed regimen among the chronic hemodialysis population, after which, the theoretical foundation for exploring the relationship between a person's locus of control and treatment adjustment is discussed. This chapter concludes with a review of locus of control and its relationship to treatment adjustment within the chronic hemodialysis population.

\section{Background Information}

Clinical investigations of patients undergoing long-term hemodialysis are in unanimous agreement as to the tremendous psychological stress constantly faced by these individuals. Fear of death, loss of income, reductions in family and social status, uncertainty about the future, lack of stamina, changes in body image, and worry about additional medical problems all contribute to one of the most stressful life situations imaginable (Goldstein \& Reznikoff, 1971; Lancaster, 1987). These psychological stressors result in varying degrees of depression and other psychopathology disorders in this population (Tynes, Ruggiero, \& Brantley, 1993). An individual's effort to cope 
with chronic hemodialysis and its demanding treatment regimen may be related to these psychological stressors. Therefore, nursing interventions and patient goal setting should be based on the assessment of various stressors in order to promote adjustment (Lancaster, 1987).

Few medical illnesses require a treatment program as demanding or as stringent as chronic hemodialysis. Adjustment to the prescribed treatment regimen of chronic hemodialysis is a complex interaction of the patient's ability to respond to diet, medication, scheduling of treatment, social and vocational expectations, and numerous other factors (Zetin, Plummer, Vaziri, \& Cramer, 1981). Individuals that are noncompliant with the prescribed treatment regimen may have severe consequences to health and survival. Plough and Salem (1982) and Kaplan De-Nour (1981) found that dietary indiscretion was the primary and immediate cause of death from congestive heart failure (a complication associated with excessive fluid intake). Cummings, Becker, Kirscht, and Levin (1981) found that fluid noncompliance is a widespread problem for more than one third of patients with end stage renal disease. Not surprisingly, patients report being persistantly preoccupied with thirst (Rosenbaum \& Ben-Ari Smira, 1986) and rank fluid compliance as the most stressful of 30 physiological and psychological stressors (Baldree, Murphy, \& Powers, 1981). 
Brown and Fitzpatrick (1988) investigated dietary compliance in 41 randomly selected dialysis clients from a large renal dialysis unit in a London teaching hospital. Twenty patients were on home hemodialysis, 1.1 were hemodialyzed at the hospital and 10 were on continuous ambulatory peritoneal dialysis (CAPD). Objective criteria to assess dietary abuse included: (a) interdialytic weight gain (IWG) to indicate fluid intake, (b) blood potassium (K) levels to assess potassium intake, and (c) serum urea (BUN) levels to reflect protein intake. Assessment of dietary abuse was made on a 4-point scale, from great abuse (4) to excellent or no abuse (1). The results revealed that $58 \%$ of the 41 subjects had difficulty with various aspects of their dietary regimen as measured by elevated interdialytic weight gains, potassium and urea blood levels.

Hartman and Becker (1978) measured regimen compliance with the following objective criteria: (a) serum phosphorus (P) level, (b) serum potassium (K) levels, and (c) interdialytic weight gain (IWG). The results of the study revealed that only 398 of 50 stable chronic hemodialysis patients were compliant with phosphorus binding medications (PBM), $74 \%$ with diet based on serum potassium levels, and $78 \%$ with fluid restriction based on interdialytic weight gain (IWG). 
The predominant methods of assessing one's ability to adapt to the prescribed treatment regimen are: (a) objective laboratory values, (b) patient self-reports, and (c) reports from dialysis personnel (wolcott et al., 1986). These methods may also identify those individuals at risk for life threatening crises and other complications. Objective measurements of treatment adjustment include the following physiological markers: (a) serum potassium levels, (b) serum phosphorus level, (c) blood urea nitrogen levels, and (d) interdialytic weight gains (Wol.cott et al., 1986). Conceptual Framework

The theoretical foundation of this study was the social learning theory which evolved from Julian Rotter's early work $(1954,1966)$. The focus of this review will be Locus of Control, hereafter referred to as LOC. The inquiry of LOC will include a discussion of the construct as introduced by Julian Rotter and the scale to measure LOC.

Rotter (1954, 1966) investigated the role of reinforcement in explaining behavior. Reinforcement acts to strengthen an expectancy that a particular behavior will be followed by the same reinforcement in the future. Rotter pointed out that the effect of reinforcement following a particular behavior depends upon whether or not the person perceives a causal relationship between his/her own behavior and the reinforcement. This perceived relationship between 
behavior and its reinforcement or outcome has been referred to as the LOC. If the person perceives that the reinforcement (outcome) is contingent upon his/her own behavior, then this belief derives from an internal LOC. On the contrary, when an individual interprets a reinforcement to one's behavior not totally a result of his/her own actions, but rather the result of luck, chance, or fate, this belief is from an external LOC according to Rotter. Rotter (1975) expressed that there were problems and misconceptions about the Internal-External scale to measure LOC. "It was developed as a broad gauge instrument... to allow for a low degree of prediction of behavior across a wide range of potential situations" (Rotter, 1975, p. 64). Rotter dealt with global life happenings, not health specific phenomena. It was recommended that a health related locus of control scale be developed in order to determine the relationship between expectancy for reinforcement and health related behavior.

K. Wallston, B. Wallston, Kaplan, and Maides developed the Health Locus of Control (HLC) Scale in 1976. The HLC Scale was further expanded upon in 1978 by $\mathrm{K}$. Wallston and B. Wallston, and is known as Multidimensional Health Locus of Control (MHLC) Scale, the tool implemented in this study. The MHLC scale measures the degree to which individuals believe that their health is controlled by internal versus 
external forces. This multifaceted scale measures three distinct dimensions: (a) internality (IHLC), (b) chance externality (CHLC), and (c) powerful others externality (PHLC) (Wallston \& Wallston, 1978). The internal locus of control segment measures the subject's beliefs about the extent to which his/her own behavior influences health. Chance locus of control measures the subject's beliefs about the extent that chance and fate influence one's health. The powerful others locus of control element of the MHLC scale measures the subject's beliefs about the extent to which doctors, nurses and other health professionals influence his/her health.

\section{Literature Review}

Rotter's Internal/External Iocus of Control (I/E) scale (1966), the Health Locus of Control (HLC) scale (Wallston, et al., 1976), and the Multidimensional Health Locus of Control (MHLC) scale (Wallston \& Wallston, 1978) have been utilized in past research to explore the relationship between locus of control and treatment adjustment in chronic hemodialysis populations.

zetin, et al. (1981) investigated the influence of locus of control to treatment adjustment in 15 chronic hemodialysis patients. They hypothesized that internals in comparison with externals would demonstrate greater physiological compliance to the dialysis regimen by 
maintaining lower predialysis serum concentrations of potassium, phosphorus, and urea nitrogen and lower weight gain between dialysis treatments. Good compliance was defined for each of the physiological variables by the criteria of Wenerowicz et al. (1978): (a) mean potassium less than $5.5 \mathrm{meq} / 1$, (b) mean phosphorus less than 4.5 $\mathrm{mg} / \mathrm{dl}$, (c) mean BUn less than $100 \mathrm{mg} / \mathrm{dl}$, and (d) mean interdialytic weight gain less than $2.6 \mathrm{~kg}$. A global compliance score was derived by assigning 1 point for each of the above four criteria if the condition was met and 0 points if it was not met, leading to a global compliance score from 0 to 4.

All 15 subjects completed Rotter's internal/external questionnaire. Analysis of Rotter's tool in relationship to global compliance scores indicated that externals had lower overall compliance, as measured physiologically. Their findings indicated that patients with a higher external locus of control had greater interdialytic weight gain (IWG), a good proxy measure of noncompliance. However, analysis of the correlations of Rotter's tool and mean serum potassium, phosphorus, and urea nitrogen levels were insignificant.

Poll and Kaplan De-Nour (1980) studied the effect of locus of control on dietary compliance in 40 chronic hemodialysis patients. They utilized Rotter's Locus of 
Control scale questionnaire. An individual's locus of control was found to correlate significantly with diet compliance. Assessment of compliance with fluid and dietary restriction was made on a 5-point scale, from excellent (5) to great abuse (1). Internals had a mean compliance score of 3.25 , whereas the externals had a mean score of only 2.15. There was a significant negative correlation between locus of control and compliance.

Brown and Fitzpatrick (1988) studied the MHLC Scale with 41 randomly chosen chronic hemodialysis patients to investigate the relationship between locus of control and dietary adjustment. The three variables examined were (a) interdialytic weight gain, (b) serum potassium, and (c) urea levels. The three measures were converted into measures of dietary compliance ranging from excellent (1), average (2), some abuse (3), and great abuse (4). Brown and Fitzpatrick's (1988) findings indicated that the level of dietary abuse was high. Fifty-eight percent of the patients showed some degree of abuse. None of the three health locus of control scales were significantly correlated with dietary abuse as measured by serum $K, B U N$, and IWG. Thus it would appear that beliefs about the control one has over one's health are not a salient influence upon complying with diet among this particular population. Clearly, the influence of locus of control on treatment adjustment particularly to 
dietary compliance and fluid restriction requires further study.

\section{Summary}

The theoretical constructs and related empirical support for the relationship between locus of control and treatment adjustment to the prescribed treatment regimen of chronic hemodialysis were presented in this chapter. The next chapter presents the methodology that was used in the study . 
Chapter 3

METHODOLOGY

This chapter begins with a description of the research design. Human subjects approval, setting, and the sample selection criteria will then be addressed. After which the development of the instrument is presented. The methods and procedures for data collection are described. The chapter concludes with the plan for data analysis.

\section{Research Design}

A prospective, nonexperimental, exploratory design was used to explore whether relationships existed among the variables utilized in this study. This design was used to examine the relationship between locus of control, dietary compliance, and fluid restriction in 31 chronic hemodialysis patients.

\section{Human Subject Approval}

The research proposal was reviewed and approved by the Human Subject Institutional Review Board at San Jose state University (Appendix A) and the Institution Review Board at the dialysis center (Appendix B). Access to the outpatient dialysis center was obtained initially by telephone contact with the Administrator of Patient Services. Upon request of the IRB, the investigator submitted an addendum (Appendix C) to the proposal which addressed the MHLC scale questionnaire 
and permitted the facility access to the results.

The 3 primary nephrologists providing medical services to participants at the dialysis center were contacted in person. An overview of the study was presented. A letter of support was received from the 3 nephrologists (Appendix D) .

Written informed consent from the participants was obtained using the consent forms approved by both Review Boards (Appendix E). The consent form states that there are no anticipated risks for participating in the study, and there are no discernible benefits to the subjects. Participants with questions or compliants were provided with the appropriate names of the individuals to contact, along with their corresponding telephone numbers.

setting

The sample for the study was recruited from an out patient chronic hemodialysis center in the south san Francisco Bay area. The facility was a free standing center that provided hemodialysis services to approximately 90 chronic hemodialysis patients. It had the capacity to dialyze 13 patients at one time. Most patients were dialyzed for 3 hours, 3 times a week.

sample size and sample selection

The criteria for sample selection included renal patients who were between 20-80 years of age and who were on 
hemodialysis treatments 3 times per week and had been for at least 5 months. Only the subjects without any medically diagnosed mental disorders, impaired level of consciousness, or inability to understand written instructions were eligible to participate. Individuals with any form of mental impairment were not eligible to participate because the MHLC scale questionnaire requires the subject to be able to read and understand English at the eighth grade level. In addition, subjects had to have a $\mathrm{Kt} / \mathrm{V}$ of 1.0 or greater and a prescribed treatment regimen that included: (a) a low potassium, (b) low protein diet, and (c) a $1000 \mathrm{cc}$ to $1500 \mathrm{cc}$ fluid restriction per day. Individuals with a $\mathrm{Kt} / \mathrm{V}$ less than 1.0 were eliminated from the study because these individuals may have elevated laboratory values as a result of inadequate hemodialysis.

Assistance was rendered by the head nurse of the dialysis center to ascertain whether the subjects met all the criteria for inclusion in the study. There were 39 potential subjects eligible to participate in this study. The researcher approached potential participants while on dialysis to explain: (a) the purpose of the research,

(b) benefits of the study, (c) potential risks involved,

(d) their rights as research participants, and

(e) protection of confidentiality. Each subject received a cover letter explaining the study and a consent form. The 
cover letter reinforced the purpose, contents, benefits, risks and confidentiality of the study. Subjects were given time to read the materials and ask questions before signing the consent form. After the consent form was signed by both the participant and investigator, a copy was given to each subject.

Out of the 39 eligible subjects in the dialysis center, 1 was in the hospital during the study, 4 refused to participate, and 2 did not return the questionnaire. Thirty-two subjects completed the questionnaire. One subject later decided not to participate and was withdrawn from the study upon request. Thirty-one patients comprised the final study sample.

Multidimensional Health Locus of Control Questionnaire The Multidimensional Health Locus of Control (MHLC) Scale was developed by $\mathrm{K}$. Wallston and $\mathrm{B}$. Wallston in 1978 (Appendix F). Permission to utilize the MHLC questionnaire in the study was granted by $\mathrm{K}$. Wallston (Appendix G). The MHLC questionnaire was designed to study and confirm that individual beliefs for engaging in health promoting behavior are primarily internal, a matter of chance, or under the control of powerful others (Lefcourt, 1981).

During the development of the MHLC scale, persons over 16 years of age who were waiting at gates in a metropolitan airport were approached by a research assistant who briefly 
described the study and asked if they would be willing to answer questions in a booklet. The booklet consisted of 81 personally worded health-related locus of control questions. of the 354 persons approached, 282 (80\%) took the booklet of questions. Forty-eight percent of this population were male, and $90 \%$ were white, with a median estimated age of $35-$ 44 years. Of the 282 booklets handed out, 125 (448) were completed and returned. Of the 125 booklets returned, 115 were utilized for the MHLC scale development. Two were returned after data analysis had begun, and 8 had to be discarded because more than $10 \%$ of the items were incomplete.

Two equivalent forms ( $A$ and $B$ ) of the MHLC scales have been developed, each consisting of three 6-item scales. Fixed response Likert scale responses ranging from strongly agree to strongly disagree were used. The alpha reliability for the MHLC scale ranged from .67 to .77 . The three MHLC dimensions are more or less statistically independent, especially the Internal Health Locus of Control (IHLC) and Powerful other Health Locus of Control (PHLC) Scales. The IHLC and Chance Health Locus of Control (CHLC) Scales are negatively correlated (but share less than $10 \%$ common variance), and the CHLC and PHLC Scales report a moderate significantly positive correlation with a shortened version 
of the Marlowe-Crowne Social Desirability Scale ( $\underline{r}=-.24$ ) (Lefcourt, 1981).

The concurrent and discriminate validity of the MHLC Scales were established by correlating them with Levenson's Internal (I), Powerful other (P), and Chance (C) Scales. The intercorrelations of the MHLC scales and the I, P, and C Scales were such that each MHLC scale correlated most highly with the theoretical counterpart among Ievenson's scales. The designation of items into the IHLC, CHLC, PHLC Scales was determined by a factor analysis that reproduced the three dimensions without error. The development of these new scales provided health researchers with a set of instruments with far greater potential usefulness than the original HLC scale. Not only can scores be obtained on three separate theoretically and empirically differentiated dimensions, but equivalent forms of the scales are available for research designs which require repeated administrations. Data Collection

All data were collected directly by the investigator using chart reviews and the 18 item Multidimensional Health Locus of Control questionnaire. After obtaining informed consent, the investigator collected data from the subjects' charts to determine if they met the criteria to participate in the study. Information obtained included: 
(a) demographic information; (b) the last three consecutive monthly predialysis serum K, P, BUN; and (c) the last 12 preceding IWG (Appendix H) .

Each subject was approached while on dialysis, and given the 18-item MHLC questionnaire with a stamped, selfaddressed, return envelope. This provided each subject with the option to either complete the form while on dialysis or take the questionnaire home and return it by mail. The data were coded to allow for anonymity. Subjects were assured that their identity would not be disclosed during the analysis or in any published report. All documents received from subjects were locked in a file cabinet in the researcher's home. Materials completed at the dialysis center were returned directly to the investigator or placed in sealed envelopes to be picked up by the investigator. For those individuals who elected to take the questionnaire home to complete, measures were taken to assure a high mail response rate. If the questionnaire was not returned within 5 days either to the dialysis center or to the investigator by mail, a follow up visit was made when the patient returned to dialysis. This follow up visit was to determine if the questionnaire had been sent or if the subject had any problems in completing it. 


\section{Data Analysis}

The plan was to use descriptive statistics to analyze the demographic characteristics of the sample. The scores from this data were entered into a computer for analysis using the statistical Package for the Social sciences (SPSS). The Pearson product-moment correlation coefficient was computed between internal LOC, powerful other LOC, chance LOC, serum potassium level, serum phosphorus level, blood urea nitrogen levels, and interdialytic weight gains.

\section{Summary}

This chapter reviewed the design, human subjects approval and site access, sample selection criteria, instrumentation, data collection procedure, and the analytical plan for the study data. The results are presented in tables and text in the following chapter. 


\section{Chapter 4 \\ ANALYSES AND INTERPRETATION OF DATA}

The purpose of this exploratory stuay was to examine the relationship between health locus of control and adjustment to the prescribed treatment regimen in 31 chronic hemodialysis patients. This chapter begins with a discription of the data collection, followed by the demographic elements of the sample. The Pearson product moment correlation coefficient for each locus of control subscale and the physiological indicators of treatment adjustment will be presented. The findings for each research question will then be addressed.

\section{Data Collection}

All data were collected by the investigator using the 18 item Multidimensional Health Locus of Control questionnaire and chart review. Names of potential patients who met the criteria for the study were obtained from the head nurse of the dialysis center. Patients were assisted with completion of the questionnaire as needed. Five subjects elected to take the questionnaire home to complete due to difficulty in completing the questionnaire while on dialysis. Three of the five subjects returned the questionnaire to the dialysis center. The two subjects who had not returned the questionnaire were visited while on 
dialysis during their next scheduled treatment to determine if they needed assistance in completing the questionnaire. Although no problems were reported, these two patients never returned their questionnaires. Materials completed at the dialysis center were returned directly to the investigator or placed in sealed envelopes to be picked up by the investigator.

The second portion of data collection was obtained through chart review. The investigator collected data from the subjects' charts to verify that they met the criteria to partake in the study. Information obtained from the chart included demographic information and physiological indicators of treatment adjustment. The data were analyzed using the Pearson product moment correlation coefficient to ascertain if there was a relationship between LOC and treatment adjustment as indicated by serum $\mathrm{K}$ levels, serum $P$ levels, BUN levels, and IWGs.

\section{Demographic Characteristics}

The convenience sample consisted of 31 renal patients from an outpatient chronic hemodialysis center in the south San Francisco Bay area. Descriptive statistics included the characteristics of the sample: (a) age, (b) sex, (c) race, (d) marital status, (e) employment status, (f) diabetic status, and $(g)$ length of time on dialysis. Of the original 
39 eligible subjects who met the criteria for the study, the final sample consisted of 31 subjects.

Table 1 summarizes the demographic characteristics of the sample. The sample consisted mainly of white, nondiabetic males. Twenty-five percent were between the ages of 25-55 years of age and 43z were 71-80 years old. The mean age was 62.5 years and the median age was 66 years. Sixty-four percent of the sample were married. More than half of the sample had been on dialysis less than 2.5 years. Table 2 summarizes the means, medians, and range values for each of the physiological indicators of treatment adjustment ( $K, P, B U N$, and IWG). The criteria for good physiological treatment adjustment, established by Wenerowicz and Associates (W\&A) (1978) are given. In addition, the percentages of the population that exceeded the criteria for each physiological variable are presented.

The criteria for optimum physiological treatment adjustment were: (a) predialysis serum potassium less than $5.5 \mathrm{meq} / 1$, (b) serum phosphorus less than $4.5 \mathrm{mg} / \mathrm{dl}$, (c) serum urea nitrogen less than $100 \mathrm{mg} / \mathrm{dl}$, and (d) interdialytic weight gain less than 2.6 kilograms. The mean score for serum potassium was $4.9 \mathrm{meq} / 1$ with a range from 3.7-6.0 meg/1. Although the mean potassium score for the sample complied with the recommended criteria for 
Table 1

Demographic Characteristics of the sample $\langle N=31)$

Characteristics Number ( $\%$ )

Gender

Male

Female

Age in Years

$25-40$

$41-55$

$56-70$

$71-80$

Ethnicity

Caucasian

Black

Hispanic

Asian

Marital status

Married

Divorced

single

widowed

Diabetic Status

Diabetic

Nondiabetic

Months on Dialysis

$$
\begin{array}{r}
5-30 \\
31-60 \\
61-100 \\
101-150
\end{array}
$$$$
151-270
$$

$22(71 \%)$

$9(298)$

$2(068)$

6 (19웅

$10(32 \%)$

$13(438)$

$19(618)$

$9(29 \%)$

$2(078)$

$1(038)$

$20(64 \%)$

$6(198)$

$2(078)$

$3(108)$

$9(29 \%)$

$22(71 \%)$

17 (55\%) (Mean 51.4 months)

$3(10 \%) \quad$ (Median 24 months)

$7(238)$

$2(06 \%)$

$2(06 \%)$ 
Table 2

Physiological Indicators of Treatment Adjustment $(N=31)$

\begin{tabular}{lccccc}
\hline & & & & W\&A & \& Pop. \\
Variable & Mean & Median & Range & Values & W\&A Values \\
\hline $\mathrm{K} \quad(\mathrm{meg} / \mathrm{I})$ & 4.9 & 5.0 & $3.7-6.0$ & $<5.5$ & 168 \\
$\mathrm{P} \quad(\mathrm{mg} / \mathrm{dl})$ & 6.4 & 6.1 & $3.3-11.5$ & $<4.5$ & 848 \\
BUN (mg/dI) & 71.8 & 77.0 & $42-100$ & $<100$ & 08 \\
IWG (kg) & 2.9 & 2.8 & $1.5-6.7$ & $<2.6$ & $58 \%$ \\
\hline
\end{tabular}

potassium, $168(n=5)$ scored greater than $5.5 \mathrm{meq} / 1$.

Therefore, $16 \%$ of the sample were in a hyperkalemic state which could have predisposed them to arrhythmias, cardiac arrest, and death.

For the entire sample the mean phosphorus level was $6.4 \mathrm{mg} / \mathrm{dl}$, nearly one and a half times the recommended level. Eighty-four percent had values greater than $4.5 \mathrm{mg} / \mathrm{dl}$ and were therefore more likely to develop disorders associated with hyperphosphatemia which may lead to renal osteodystrophy.

The mean BUN level was $71.8 \mathrm{mg} / \mathrm{dl}$ with a range from 48-100 mg/dI. The sample meets the criteria for good physiological adjustment in regards to BUN. 
Interdialytic weight gains ranged from 1.9 to $6.7 \mathrm{~kg}$. with a mean value of $2.9 \mathrm{~kg}$. Fifty-four percent exceeded the recommended interdialytic weight gain of $2.6 \mathrm{~kg}$ and consequently were at risk for life threatening complications linked with fluid overload such as congestive heart failure and pulmonary edema.

In conclusion, this sample does not demonstrate good treatment adjustment according to their physiological markers. Sixteen percent are predisposed to complications associated with hyperkalemia; $84 \%$ may be more likely to experience calcium and phosphorus imbalances associated with hyperphosphatemia; and $54 \%$ are apt to develop complications related to fluid overload.

\section{Locus of Control}

The Multidimensional Health Locus of Control scales (MHLC) yielded scores on three subscales (Wallston et al., 1978). These subscales measured the variables of internal, chance, and powerful other locus of control. Each subscale had a possible 6 to 36 score for a possible range of 30 .

In Table 3, the means, standard deviations, and ranges for each subscale of the MHLC scale are presented. The mean score on the internal LOC was 27.9 with a standard deviation of 5.0. The mean score on the chance LOC was 20.4 with a 
Table 3

Multidimensional Health Locus of Control $(N=31)$

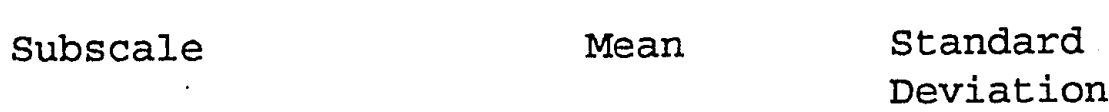

$\begin{array}{lll}\text { Internal } & 27.9 & 5.0 \\ \text { Chance } & 20.4 & 6.5 \\ \text { Powerful other } & 26.3 & 7.9\end{array}$

standard deviation of 6.5. The mean score on the powerful other LOC was 26.3 with a standard deviation of 7.9 .

Table 4, reports the correlation coefficients between the four physiological indicators of treatment adjustment and the three locus of control scores. Serum potassium, phosphorus, blood urea nitrogen levels and interdialytic weight gains were each correlated with each of the internal, chance, and powerful other scores.

The data indicated that there were no statistically significant relationships between internal locus of control and any of the physiological measurements of treatment adjustment. There were no significant correlations between chance locus of control (CLOC), powerful other (PLOC), serum potassium, serum phosphorus, and interdialytic weight gains. 
Table 4

Correlations Between Physiological Indicators of Treatment

Adjustment and Locus of Control $(\mathrm{N}=31)$

Physiolgical

Indicator

Potassium

IWG

Phosphorus

Blood

Urea Nitrogen

$\mathrm{P}=.02 *$

$$
\underline{p}=.92
$$

$\underline{r}=.28$

$\underline{r}=-.35$

$\underline{r}=-.09$

$\underline{p}=.13$

$p=.06$

$p=.63$

$\underline{r}=-.02$

$\underline{I}=.03$

$p=.88$

$\underline{r}=-.42$

$\underline{r}=-.30$

$\underline{p}=.11$

Powerful Other

$$
\underline{r}=.00
$$$$
p=.99
$$

$\underline{r}=-.57$

$\mathrm{p}=.0008$ *

$\underline{x}=.09$

$p=.64$ $\underline{r}=-.09$

$p=.62$

* Significant $p<.05$

However, there were significant negative correlations

between CLOC and blood urea nitrogen (BUN) ( $\underline{r}=-.43, \underline{p}=.02$ ) and PLOC and BUN ( $\underline{r}=-.57, \underline{p}=.0008)$. This strong relationship between CLOC and BUN or PLOC and BUN proposes that subjects who scored high in control by fate and powerful others had lower BUN levels, and therefore they may be more compliant with their dietary restriction of protein. 
However, it should be pointed out that the BUN level for this sample was within the recommended level (<100mg/dl), whereas the $\mathrm{K}, \mathrm{P}$, and IWG have exceeded recommended level. This suggests the following: (a) it may be easier to control an individual's protein consumption in comparison to potassium, phosphorus, and fluid intake; and (b) the hemodialysis procedure may maintain BUN levels more effectively than potassium and phosphorus levels, and interdialytic weight gain.

\section{Sumary}

In summary, a small convenience sample of 31 chronic hemodialysis patients reported their locus of control on a questionnaire. Physiological indicators of treatment adjustment were obtained from chart reviews. In reference to research questions number 1,2 , and 4 , the results of this study do not support a relationship between LOC and serum potassium, phosphorus, or interdialytic weight gain within this population. There was a statistically significant positive relationship between powerful other, chance locus of control, and BUN (research question 3). Therefore, in this population, the measurement of one's LOC can only explain how one may adjust to the treatment regimen in regards to protein intake. It does not explain how one responds to the other dietary limitations such as potassium, 
phosphorus and fluid restrictions associated with the complex treatment regimen of chronic hemodialysis.

In this chapter, analyses of the results obtained through chart reviews and scores from the Multidimensional Health Locus of Control scale questionnaire were presented. A discussion of the findings, results, limitations, and recommendations for nursing research will be included in the following chapter. 
Chapter 5

DISCUSSION, IMPLICATIONS AND RECOMMENDATIONS

Summary

The purpose of this study was to explore the relationship between locus of control and treatment adjustment for 31 chronic hemodialysis patients. This study determined the locus of control, reported physiological measurements of treatment adjustment, and measured the relationship between locus of control and physiological indicators of treatment adjustment among 31 chronic hemodialysis patients. This chapter draws conclusions from the study and identifies limitations to the study. This chapter concludes with the recommendations for further study and the implications for nursing practice.

The results of this study suggest that there may not be a strong relationship between locus of control and the physiological indicators of treatment adjustment except for chance LOC, powerful other LOC, and blood urea nitrogen levels. Thus, it would appear that beliefs about the control one has over his/her health may not be a salient influence upon how one adjusts to the prescribed treatment regimen of chronic hemodialysis.

The Pearson's product moment correlation coefficients revealed negative relationships between powerful other locus 
of control and blood urea nitrogen levels, and there were negative relationships between chance locus of control and blood urea nitrogen levels. These correlations may suggest that subjects who score high in chance LOC and control by powerful others comply with their restricted protein intake better than those who score high on the internal locus of control subscale.

The prescribed hemodialysis treatment regimen is a complex program that requires long term psychological, sociological, and physiological adaptations. In addition, it imposes a measure of dependency upon all chronic hemodialysis patients, and therefore, it is essential that all factors contributing to successful treatment adjustment be explored. Factors linked to optimum treatment adjustment may include: (a) one's culture, (b) socioeconomic status, (c) education, (d) age, (e) disability, (f) social support, (g) perceived health status, (h) perceived control over health, (i) knowledge pertaining to treatment compliance, (j) staff-patient relationship, and (k) length of time on dialysis (wolcott et al., 1986). These confounding variables were not controlled for in this study.

Limitations

There were several limitations to the study. First, this exploratory study utilized a small, convenience sample. Therefore, the results are limited to this specific target 
population of 31 subjects and cannot be generalized to all chronic hemodialysis patients. Second, the MHLC questionnaire measures a subject's LOC. An individual's LOC may not be totally orientated to internal, chance, or powerful other, and it may vary depending upon certain aspects of the treatment regimen. Third, the results of this study did not investigate other variables that may influence compliance such as: (a) age, (b) gender, (c) employment status, (d) marital status, (e) support systems, (f) depression, (g) transplant failure, (h) other chronic medical disabilities, (i) economic status, (j) perception of illness, and (k) length of time on dialysis. Fourth, the terms internal, chance, and powerful other locus of control can only depict the subject's more common tendencies regarding the relationship of their health with adjustment to the prescribed treatment regimen. Another Iimitation to this study is that the MHLC questionnaire allows subjects to report data about themselves. Self reported information is a limitation in all questionnaire completion (Burns \& Grove, 1987). Furthermore, the researcher must assume that the subject will be able to read and understand the questions, and then respond accurately and honestly to all 18 items. 


\section{Recommendations for Further study}

1. A replication of this study in other dialysis centers that utilize a larger population would yield valuable information to dialysis personnel.

2. A longitudinal study that examines how long term treatment adjustment to the prescribed regimen correlates with locus of control would provide valuable data over time.

3. A study that utilizes current criteria for determining compliance and treatment adjustment would provide valuable data that reflects the present chronic hemodialysis population. This study defined optimal treatment adjustment according to the critera established in 1978 by Wenorowicz, et al. It would be valuable to apply recent standards of treatment adjustment such as those established in 1990 by the ESRD Program Management and Medic. Information System.

4. A study that focuses on the possibility of changing an individual's locus of control through extensive psycholological counseling would provide valuable data for nurses in health promotion and patient education.

5. A study that explores the relationship between locus of control and treatment adjustment through an incentive program would provide useful information to dialysis personnel. For example, it may be possible to change one's LOC orientation and promote treatment 
adjustment by offering incentives, such as shorter dialysis treatments.

6. A study that examines the relationship of survival and mortality of chronic hemodialysis patients and their MHLC scores would generate valuable data for all health care providers.

7. A study that explores the significance "powerful others" have in contributing to an individual's level of treatment adjustment would assist nurses in health promotion.

8. A study that examines treatment adjustment and multiple psychosocial elements within the chronic hemodialysis population such as the following: (a) social support, (b) perceived health status, (c) marital status, (d) employment, and (e) education would generate valuable data. These factors would provide more complete and concrete data regarding one's ability to adjust to the complex treatment modality of hemodialysis. This information would be valuable for all dialysis personnel.

9. A study that examines the relationship between various psychological stressors and their influence on an individual's ability to cope with the demands of chronic hemodialysis and the prescribed treatment regimen would provide valuable information. Psychological stressors to be examined include: (a) fear of death, (b) loss of income, 
(c) lack of stamina, (d) changes in body image, and

(e) uncertainty about the future.

10. Further research is needed to predict a cause and effect relationship between locus of control and treatment adjustment to the chronic hemodialysis regimen.

Implications For Nursing Practice

Understanding an individual's locus of control could be helpful to nurses who wish to promote adherence to the prescribed treatment regimen in the chronic hemodialysis population. If a relationship between LOC and treatment adjustment was supported, it would be benefical during the initial assessment of a patient beginning hemodialysis to measure the patient's LOC. Once an individual's locus of control is identified, appropriate teaching strategies could be implemented to promote treatment adjustment to the prescribed treatment regimen of chronic hemodialysis.

An individual with an internal locus of control is reinforced by his/her personal belief that a particular behavior is directly linked to his/her health. This type of patient may benefit from a one on one teaching strategy that reinforces personal control over one's health status and treatment adjustment. This same information might be given in the written form of a pamphlet or brochure. This is a cost effective way to deliver health promoting information. 
A patient with a chance locus of control may feel that he/she has no control over his/her health and therefore his/her behavior is not connected with health or treatment adjustment. Individuals with an external LOC will need repetitive contact with health promoting information. Personal contacts and individual experience may be the best method of teaching health promotion to these types of individuals. The nurse may be able to encourage health promoting activities associated with treatment adjustment through individualized incentive programs.

Lastly, an individual with a powerful other locus of control orientation may associate one's health status to be dependent upon the behaviors of others such as family, friends, and health professionals. This individual might benefit more from receiving health promoting information from one on one conversation with the nurse or from a guest speaker who is recognized as an expert on the subject. The focal point for nursing in this instance is to involve those significant "powerful others" in the learning process. There was a strong statistically significant negative correlation between powerful other LOC (PLOC) and blood urea nitrogen levels $(\underline{r}=-.57, \underline{p}=.0008)$. Therefore, nurses need to investigate the significance of "powerful others" and their influence on treatment adjustment. 
Strategies for promoting treatment adjustment in the chronic hemodialysis population will vary. It is important to keep in mind that chronic hemodialysis patients are very diversified. Therefore the nurse must be attentive to new modes for teaching a variety of individuals and groups.

A person's locus of control is only one psychological factor that may play a part in predicting adjustment and compliance to the treatment regimen. Other psychological factors include: (a) cultural background, (b) socioeconomic status, (c) education, (d) age, (e) disability, (f) social support, (g) perceived health status, (h) perceived control over health, (i) knowledge pertaining to treatment compliance, (j) staff-patient relationship, and (k) length of time on dialysis. These additional factors may play a significant role in determining treatment adjustment among the chronic hemodialysis populations.

Conclusion

This study found that locus of control was related to treatment adjustment in regards to one aspect of dietary compliance. There was a statistically significant negative correlation between chance locus of control, powerful other locus of control and serum blood urea nitrogen levels. However, the statistically significant relatonship between chance locus of control and serum blood urea nitrogen is not consistent with findings from past research. Moreover, the 
findings from this study do not support a relationship between locus of control, serum potassium levels, serum phosphorus levels, and interdialytic weight gains. 
REFERENCES 


\begin{abstract}
References
Baldree, K., Murphy, S., \& Powers, M., (1981). Stress identification and coping patterns in patients on hemodialysis. Nursing Research, 31, 107-112.
\end{abstract}

Bandura, A. (1976). Social learning and personality development. New York: Holt, Rinehart \& Winston. Bandura, A. (1977). Social learning theory. Princeton, NJ: Prentice Hall.

Blackburn. S. (1977). Dietary compliance of chronic hemodialysis patients. Journal of the American Dietetic Association, 70, 31-37.

Brock, M. (1990). Uncertainty, information needs, and coping effectiveness of renal families. American Nephrology Nurses Association, 17, 242-267.

Brown, J. \& Fitzpatrick, R. (1988). Factors influencing compliance with dietary restrictions in dialysis patients. Journal of Psychosomatic Research, 32, $191-196$.

Burns, N. \& Grove, S. (1987). The practice of nursing research. Philadelphia, PA: Saunders.

Cummings, K., Becker, M., Kirscht, J., \& Levin, N. (1982). Psychosocial factors affecting adherence to medical. regimens in a group of hemodialysis patients. Medical Care, 20, $567-580$. 
Goldstein, A. \& Reznikoff, M. (1971). Suicide in chronic hemodialysis patients form an external locus of control framework. American Journal of Psychiatry, 127, 124-127. Hartman, P. \& Becker, M. (1978). Noncompliance with prescribed regimen among chronic hemodialysis patients: A methods of prediction and education diagnosis. Dialysis and Transplantation, $7,978-986$.

Hudak, C., Gallo, B., \& Lohr, T. (1986). Critical care nursing (4th ed.). Philadelphia, PA: Lippincott. Kaplan De-Nour, A. \& Czaczkes, J. (1976). The influence of patient's personality on adjustment to chronic dialysis. Journal of Nerve and Mental Disorders, 162, 323-333. Kaplan De-Nour, A. (1981). Prediction of adjustment to chronic hemodialysis. New York: Plenum.

Kirilloff, L. (1981). Factors influencing the compliance of hemodialysis patients with their therapeutic regimen. AANNT, $8,15-20$.

Lancaster, I. (Ed.) (1987). Core curriculm for nephrology nursing. Pitman, NJ: Jannetti.

Lefcourt, H. (1981). Research with the locus of control construct. New York: Academic Press.

Levin, A. \& Schulz, M. (1980). A multidimensional health locus of control and compliance in low and high participation hemodialysis programs. Unpublished master's thesis, University of Wisconsin: Madison. 
Levy, N. B. (1974). Living or dying: Adaptation to

hemodialysis. Chicago: Bannerstone House.

Levy, N.B. (1980). The uncooperative patient with ESRD, causes and treatment. Proceedings of the European

Dialysis and Transplant Association, 17, 523-530.

Lewis, S., \& Collier, I. (1992). Medical surgical nursing

(3rd ed.). St. Louis, MO: Mosby.

Plough, A., \& Salem, S. (1982). Social and contextual

factors in the analyses of mortality in end stage renal

disease: Implications for health policy. American

Journal of Public Health, 72, 1293-1295.

Poll, I., \& Kaplan De-Nour, A. (1980). Locus of control and adjustment to chronic hemodialysis. Pyschological

Medicine, 10, 153-157.

Procci, W. (1978). Dietary abuse in maintenance

hemodialysis patients. Psychosomatics, 19, 16-24.

Procci, W. (1981). Psychological factors associated with

severe abuse of the hemodialysis diet. General Hospital

Psychology, $3,111-118$.

Rosenbaum, M. , \& Ben-Ari Amira, K. (1986). Cognitive and personality factors in the delay of gratification of hemodialysis patients. Journal of Personality and Social Psychology, 51, 357-364. 
Rosenstock, I., strecher, V. \& Becker, M. (1988). Social learning theory and the health belief model. Health Education Quarterly, 15, 175-183.

Rotter, J. (1954). Social learning and clinical psychology. New York: Prentice Hall.

Rotter, J. (1966). Generalized expectancy for internal vs external control of reinforcements. Psychological Monographs, 80, $609-615$.

Rotter, J. (1975). Some problems and misconceptions related to the construct of internal versus external control of reinforcement. Journal of consulting Clinical

Psychology, 43, 56-67.

Sand, P., Livingston, G., \& Wright, R. (1966). Psychological assessment of candidates for a hemodialysis program. Annals of Internal Medicine, 64, 602-610. Speroles, K. (1977). Health locus of control and knowledge of hemodialysis and health maintenance of patients with chronic renal failure. Unpublished master's thesis, Virginia Commonwealth University, Virginia. Thelan, L., Davie, J., \& Urden, L. (1990). Textbook of Critical Care Nursing. Missouri: Mosby. Transpacific Renal Network. (1991). Annual data report. Sausalito, CA: Author. 
Tynes, I., Ruggiero, L., \& Brantley, P. (1993). Health locus of control and psychopathology in 90 hemodialysis patients. Dialysis and Transplantation, 22, 142-146. Urdang, L. \& Swallow, H. (Eds.) (1983). Mosby's medical and nursing dictionary. St. Louis, MO: Mosby Wallston, B., Wallston, K., Kaplan, G., \& Maides, S. (1976). Development and validation of the Health Locus of Control (HLC) scale. Journal of Consulting Clinical Psychology, 44, $580-585$.

Wallston, K. \& Wallston, B. (1978). Development of the Multidimensional Health Locus of Control (MHLC) scale. Health Education Monographs, $6,160-170$.

Wenerowicz, W., Riskind, J., \& Jenkins, P. (1978). Locus of control and degree of compliance in hemodialysis patients. Journal of Dialysis, 2, 495-505. Wolcott, D.L., Maida, C.A., Diamond, R., \& Nissenson, A. (1986). Treatment compliance in end-stage renal disease patients on dialysis. American Journal Nephrology, 6 , $329-338$.

Zetin, M., Plummer, M., Vaziri, N., \& Cramer, M. (1981) Locus of control and adjustment to chronic hemodialysis. Clinical Experience Dialysis and Apheresis, $5,319-334$. 


\section{APPENDIX A \\ San Jose State University's Human-Subjects-Institutional Review Board Approval}


Date: March 18, 1992

The Human Subjects-Institutional Review Board has approved your request to use human subjects in the study entitled:

"Locus of Control: A Predictor of Dietary Compliance and Fluid Restriction in Chronic Hemodialysis"

This approval is contingent upon the subjects participating in your research project being appropriately protected from risk. This includes the protection of the anonymity of the subjects' identity when they participate in your research project, and with regard to any and all data that may be collected from the subjects. The Board's approval includes continued monitoring of your research by the Board $=0$ assure that the subjects are being adequately and properly protected from such risks. If at any time a subject becomes injured or complains of injury, you must notify Dr. Serena stanford immediately. Injury includes but is not limited to bodily harm, psychologicalatrauma and release of potentially damaging personal information. 's

please also be advised that each subject needs to be fully informed and aware that their participation in your research project is voluntary, and that he or she may withdraw from the project at any time. Further, a subject's participation, refusal to participate or withdrawal will not affect any services the subject is receiving or will receive at the institution in which the research is being conducted.

If you have questions, please contact me at 408-924-2480.

cC: Emilie Musci, Nursing 
Appendix B Agencey's Institutional Review Board Approval 


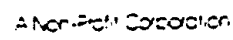

April 3, 1992

Melinda Zimmer-Rankin

Dear Melinda:

This letter is to confirm our phone conversation of yesterday. Satellite's IRB did approve your request 10 study, as described in your proposal, the patients in our facility for your research.

As we discussed, you will need to revise the MHLC questionnaire letter (page 11) and resubmit it to me for approval before disseminating it to the parients.

All of your research work will need to be done at times other than your scheduled work time as a Staff Nurse in SDC . $\therefore$ This would also include time spent collecting dara and demographic information. While you are interacting with the patients as pan of your research, you must wear a name sag indicating that you are there as a San Jose Stase University graduase student rather than an SDC employee.

You will need to meet with to determine mutually agreed upon times for you to be in the facility performing your research. You and : will also need to plan a time for a staff inservice to explain your project before you begin your research work in the facility.

We wish you good luck in this endeavor, and look forward to seeing the results.

Sincerely,

Director of Patiens Care Services

$A R: g w$ 
Appendix C

Addendum 
Health Locus of Control: A Predictor of Dietary Compliance and Fluid Restriction in Chronic Hemodialysis

An Addendum to the Research Proposal

Included in the methodology section entitled site access, the following statement will be added: Upon completion of this research study, a copy in its entirety will be made available to Satellite Dialysis Centers, Inc., upon their request. 


\section{Appendix D \\ Letter of support from Physicians}




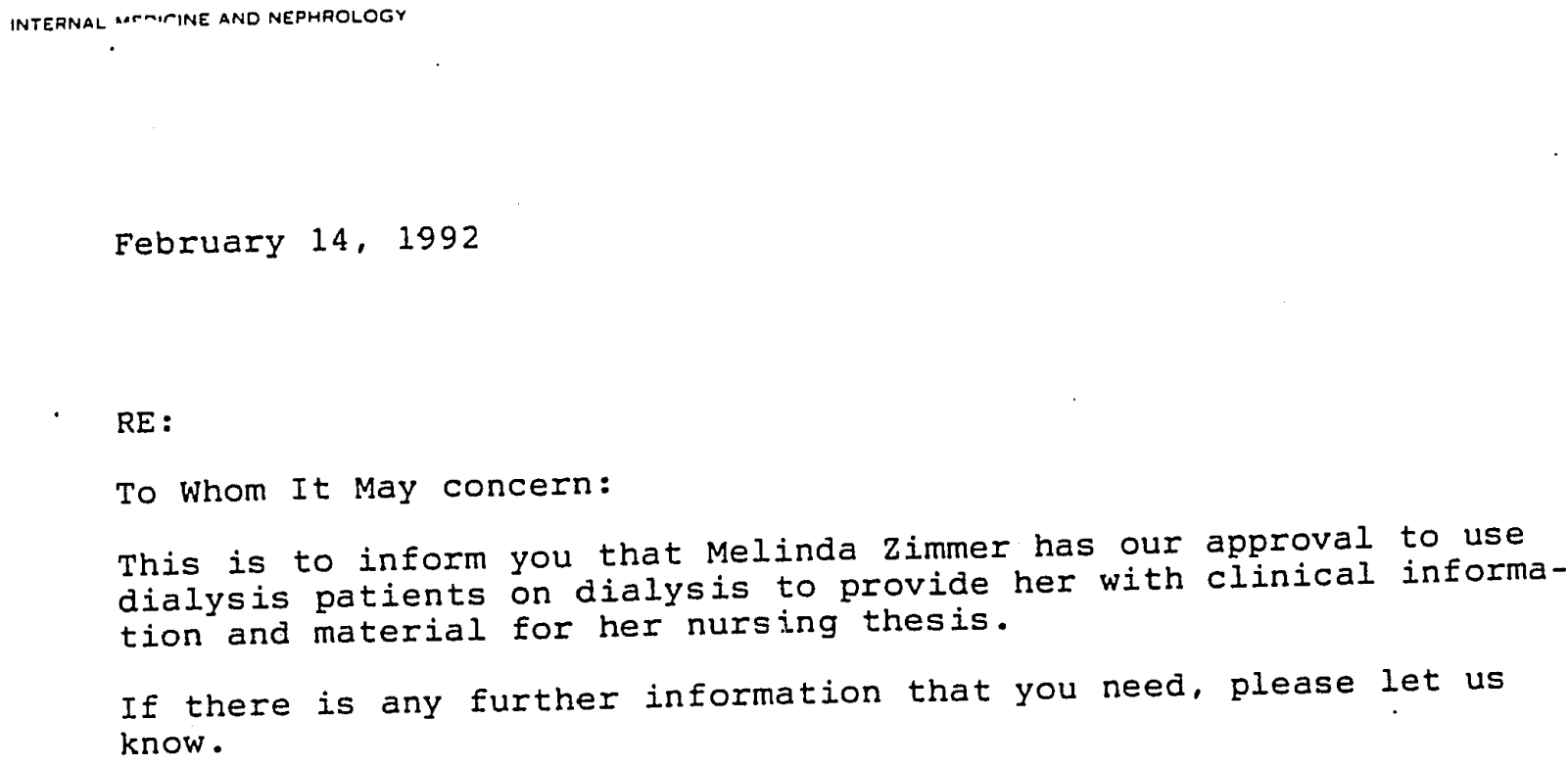


Appendix E

Cover Letter and Consent Form 
Date

Dear

I am a student at san Jose state University working towards a Master of Science Degree in Nursing Education. For my thesis I am doing a research study on the adjustment to the prescribed hemodialysis regimen focusing on dietary compliance and fluid restriction. By means of the enclosed questionnaire I hope to explore the relationship between locus of control and treatment adjustment.

Your physician, ( $\mathrm{Dr}$, Dr. and Dr. ; support my efforts in this project. The findings of this study will help me provide the health care professionals with a greater understanding of the locus of control construct and will facilitate the development of appropriate interventions readily needed to facilitate and improve treatment adjustment, promote health, and prevent complications.

I am asking for your assistance in completing this questionnaire. The enclosed questionnaire should take less than 10 minuces to complete. You can be assured that any information that can be identified with you will remain confidential and disclosed only with your consent.

I truly appreciate your time, cooperation and honest response in completing this form. This research is designed to assist hemodialysis patients like yourself adjust to the stringent complex treatment regimen associated with

hemodialysis. The results of the study will be available to you upon your request. Please feel free to contact me with and questions or concerns regarding this questionnaire. I will look forward to your response.

Sincerely, 


\section{Consent Form \\ AGREEMENT TO PARTICIPATE IN RESEARCH \\ SAN JOSE STATE UNIVERSITY}

RESPONSIBLE INVESTIGATOR; Melinda Zimmer-Rankin

TITLE OF PROTOCOL; LOCUs of Control: A predictor of Treatment Adjustment in Chronic Hemodialysis.

I have been asked to participate in a research study that is exploring the relationship between health locus of control and treatment adjustment to chronic hemodialysis focusing on dietary compliance and fluid restriction. The results of this study will help health care professionals gain a fuller understanding of locus of control and treatment adjustment in order to develop appropriate interventions.

I understand that

1) I will be asked to complete an 18-item questionnaire. It will take me about 10 minutes to complete. I will return it to the primary investigator within 2 weeks:

2) There are no anticipated risks to me in this study. However, I may experience some psychological discomfort while completing the questionnaire due to the sensitive nature of the questions.

3) 'There are no discernible benefits to me, however the results may facilitate appropriate interventions that will promote adjustment to the prescribed treatment regimen of which $I$ and future hemodialysis patients must live by.

4) The results from this study may be published, but any information from this study can be identified with me will remain confidential and will be disclosed only with my permission.

5) Any questions about my participation in this study will be answered by Melinda Zimmer-Rankin. 
6) Complaints about the procedures may be presented to Dr. Emilie Musci, Department of Nursing, Faculty Advisor, (408) 924-3130. For questions or complaints about research participants' rights contact serena Stanford, Ph.D., Associate Academic Vice President for Graduated Studies and Research, (408) 924-2480.

7) My consent is given voluntarily with no coercion. I may refuse to participate, and I may withdraw at any time.

8) I have received a copy of this consent form.

MY SIGNATURE INDICATES THAT I HAVE READ THE INFORMATION GIVEN ABOVE AND THAT I HAVE DECIDED TO PARTICIPATE.

Date Participant's signature Investigator's signature 


\section{APPENDIX F}

MHLC Scale Questionnaire 
MHLC

This is a questionnaire designed to determine the way in which different people view certain important healthrelated issues. Each item is a belief scale which ranges from strongly disagree (1) to strongly agree (6). For each item I would like you to circle the number that represents the extent to which you agree or disagree with a statement. The more strongly you agree with the statement, then the higher will be the number you circle. The more strongly you disagree with a statement, then the lower will be the number you circle. Please make sure that you answer every item and that you circle only one number per item. This is a measure of your personal beliefs; obviously, there are no right or wrong answers.

Please answer these items carefully, but do not spend too much time on any one item. As much as you can, try to respond to each item independently. When making your choice, do not be influenced by your previous choices. It is important that you respond according to your actual beliefs and not according to how you feel you should believe or how you think we want you to believe. 
1. If I get sick, it is my own behavior which determines how soon I get welI again.

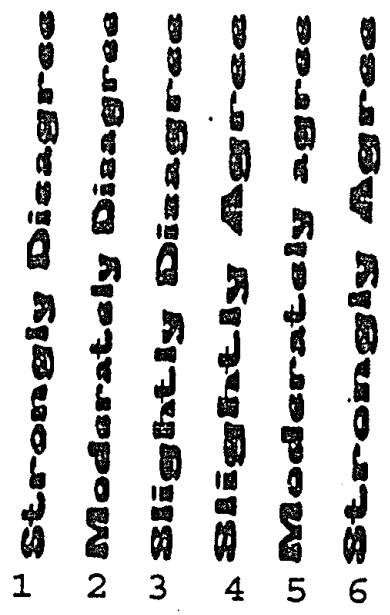

2. No matter what I do, if I am going to get sick, I will get sick.

$\begin{array}{llllll}1 & 2 & 3 & 4 & 5 & 6\end{array}$

3. Having regular contact with my physician is the best way for me to

$\begin{array}{llllll}1 & 2 & 3 & 4 & 5 & 6\end{array}$ avoid illness.

4. Most things that affect my health happen to me by accident.

$\begin{array}{llllll}1 & 2 & 3 & 4 & 5 & 6\end{array}$

5. Whenever I don't feel well, I should $1120 \begin{array}{llllll} & 2 & 4 & 5 & 6\end{array}$ consult a medically trained professional.

6. I am in control of my health.

$\begin{array}{llllll}1 & 2 & 3 & 4 & 5 & 6\end{array}$

7. My family has a lot to do with my becoming sick or staying healthy.

$\begin{array}{llllll}1 & 2 & 3 & 4 & 5 & 6\end{array}$

8. When I get sick I am to blame.

$\begin{array}{llllll}1 & 2 & 3 & 4 & 5 & 6\end{array}$

9. Luck plays a big part in determining $\begin{array}{llllll}1 & 2 & 3 & 4 & 5 & 6\end{array}$ how soon I will recover from an illness. 


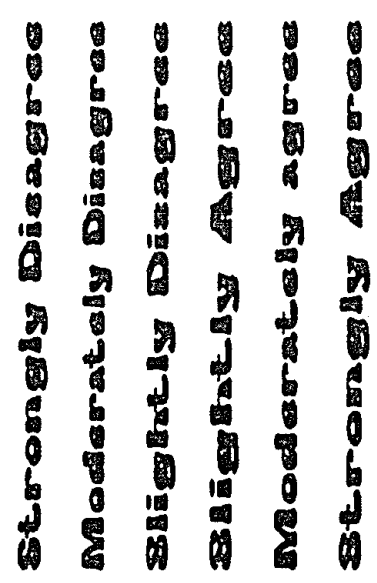

10. Health professionals control my health. $\begin{array}{llllll}1 & 2 & 3 & 4 & 5 & 6\end{array}$

11. My good health is largely a matter of $\begin{array}{lllllll}1 & 2 & 3 & 4 & 5 & 6\end{array}$ good fortune.

12. The main thing which affects my health $1 \begin{array}{llllll} & 2 & 3 & 4 & 5 & 6\end{array}$ is what I myself do.

13. If I take care of myself, I can avoid $\begin{array}{lllllll}1 & 2 & 3 & 4 & 5 & 6\end{array}$ illness.

14. When I recover from an illness, it's $\begin{array}{llllll}1 & 2 & 3 & 4 & 5 & 6\end{array}$ usually because other people ( for example, doctors, nurses, family, friends) have been taking good care of me.

15. No matter what I do, I'm likely to get $\begin{array}{lllllll}1 & 2 & 3 & 4 & 5 & 6\end{array}$ sick.

16. If it's mean to be, I will stay

$\begin{array}{llllll}1 & 2 & 3 & 4 & 5 & 6\end{array}$ healthy.

17. If I take the right actions, I can stay healthy.

$\begin{array}{llllll}1 & 2 & 3 & 4 & 5 & 6\end{array}$

18. Regarding my health, I can only do what my doctor tells me to do.

$\begin{array}{llllll}1 & 2 & 3 & 4 & 5 & 6\end{array}$ 
Appendix G

Permission to Use the MHLC Questionnaire 
VANDERBILT UNIVERSITY

To: Fellow Health Researcher

From: Kenneth A. Wallston, Ph.D.

Thank you for your interest in the Health Locus of Control Scales. Please excuse this form response, but I have so many inquiries requiring sinilar replies that I have found this to be an effictent means of disseminating information.

You have my permission to utilize Form A or B of the Matc scales in any health related research you are doing. Hy only request is that you keep inforad of any results you obtain using the scales. In that way I hope to concinue to serve as a clearinghouse for information about the scales.

We have recently developed Form $C$ of the rutc scales, an instrumene which can easily be made specific to any existing medically-related condition which your subjects might have (e.g., diabetes, cancer, high blood pregsure, migralne headaches, arthritis, chemical dependencles, etc.) He have usad Form $C$ as an "Arthritis Locus' of Control Scale" and are generally pleased with its psychometric properties. If you think such an instrment would be helpful in your research and if you are wllling to share your daca back with us, we would be pleased to make it avallable to you.

If you wish us to send you additional material, please complete and return the enclosed form. For most items there is a small charge to cover duplication and postage.

If you have more specific.questions, don't hesitate to contact me. Please remember to send me information on any use you make of these scales. I have included a usage questionnaire to facilitate your doing so. I look forward to hearing from you.

P.S. I have enclosed a copy of a brief article I just wrote on the importance of placing measures of Health Locus of Control in a Theoretical Context. I hope you find it interesting and stimulating. 
APPENDIX $H$

Data Collection Form 
Data Collection Form 1: Chart Review Information

Number:

Patient's Initials:

Doctor:

Age :

Race: Sex: Martial status: Living alone: $(Y / N)$

Education:

occupation: Presently employed $(Y / N)$

Diabetic (Yes/No)

status post transplant rejection (yes/no)

Diagnosis :

Number of months on dialysis:

Actively on transplant list:

Low potassium diet (yes/no)

Low protein diet (yes/no)

$1500 \mathrm{cc}$ Fluid restriction per day (yes/No)

$\mathrm{KT} / \mathrm{V}>1.0$ (yes/no)

Predialysis: Month 1 Month 2

Month 3

K

P

BUN

Interdialytic weight Gain

(Last 12 consecutive treatments)

1.
2
3
4
5.
6.

$$
\begin{array}{r}
7 . \\
8 . \\
9 . \\
10 \\
11 . \\
12 .
\end{array}
$$

***Iigible to participate in the study (yes/no) 